\title{
Molecular Determinants Controlling NMDA Receptor Synaptic Incorporation
}

\author{
Granville P. Storey, Ximena Opitz-Araya, and Andres Barria \\ Department of Physiology and Biophysics, University of Washington School of Medicine, Seattle, Washington 98195-7290
}

Synaptic incorporation of NMDA receptors (NMDARs) is regulated by GluN2 subunits with different rules controlling GluN2A- and GluN2B-containing receptors; whereas GluN2B-containing receptors are constitutively incorporated into synapses, GluN2A incorporation is activity-dependent. We expressed electrophysiologically tagged NMDARs in rat hippocampal slices to identify the molecular determinants controlling the mode of synaptic incorporation of NMDARs. Expressing chimeric GluN2 subunits, we identified a putative $\mathrm{N}$-glycosylation site present in GluN2B, but not in GluN2A, as necessary and sufficient to drive NMDARs into synapses in an activityindependent manner. This suggests a novel mechanism for regulating activity-driven changes and trafficking of NMDARs to the synapse.

\section{Introduction}

Unique properties allow NMDA-type glutamate receptors to play a critical role during maturation of neuronal circuits, synaptic plasticity, and pathology (Cull-Candy et al., 2001; Bliss et al., 2003; Cline and Haas, 2008).

The NMDA receptor (NMDAR) is an obligate heteromultimer composed of glycine-binding GluN1 subunits and one or more of the glutamate binding GluN2 subunits (A-D), or a combination of GluN2 and GluN3 subunits (Traynelis et al., 2010). GluN1-GluN3 combination may also exist, forming a glycinergic receptor (Chatterton et al., 2002). Glutamate-binding GluN2 subunits control fractional $\mathrm{Ca}^{2+}$ currents (Burnashev et al., 1995; Sobczyk et al., 2005), temporal activation profiles (Erreger et al., 2005), and allow differential interactions with signaling and scaffolding molecules (Barria and Malinow, 2005; Kim et al., 2005). Thus, GluN2 subunit composition affects properties of NMDARs and synaptic plasticity (Barria and Malinow, 2005; Zhou et al., 2007; Foster et al., 2010).

The predominant GluN2 subunits in mammalian hippocampus, GluN2A and GluN2B, exist primarily as diheteromeric GluN1/ GluN2A or GluN1/GluN2B complexes. Only a small fraction exists as triheteromeric GluN1/GluN2A/GluN2B receptors (Al-Hallaq et al., 2007). GluN2B is expressed prenatally and is required for normal neuronal pattern formation and viability of the animal (Kutsuwada et al., 1996). In contrast, GluN2A subunit expression and synaptic incorporation increases progressively with age (Monyer et al.,

\footnotetext{
Received Oct. 22, 2010; revised March 3, 2011; accepted March 9, 2011.

Author contributions: A.B. designed research; G.S. and X.0.A. performed research; G.S. and A.B. analyzed data; A.B. wrote the paper.

This work was supported by a National Alliance for Research on Schizophrenia and Depression Young Investigator Award and National Institutes of Health-National Institute of Neurological Disorders and Stroke Grant R01NS060756 (to A.B.), and Grant PHS NRSA 2T32 GM007270 from National Institute of General Medical Sciences (to G.S.).

Correspondence should be addressed to Andres Barria, Department of Physiology and Biophysics, University of Washington School of Medicine, 1705 NE Pacific Street, HSB G-424, Seattle, Washington 98195-7290. E-mail: barria@u.washington.edu.

DOI:10.1523/JNEUROSCI.5553-10.2011

Copyright $\odot 2011$ the authors $\quad 0270-6474 / 11 / 316311-06 \$ 15.00 / 0$
}

1994; Sheng et al., 1994; Flint et al., 1997; Stocca and Vicini, 1998). This developmental switch in synaptic NMDAR subunit composition from GluN2B- to GluN2A-containing receptors requires synaptic activity or sensory experience and accelerates the decay rate of evoked NMDAR-dependent EPSCs (Yashiro and Philpot, 2008).

However, it is not clear how neuronal activity regulates the subunit composition of synaptic NMDARs. Recent evidence indicates that GluN2 subunits regulate delivery of receptors to synapses with different rules controlling GluN2A- and GluN2B-containing receptors. Synaptic incorporation of GluN2B-containing receptors is constitutive and does not require synaptic transmission. In contrast, GluN2A synaptic incorporation is activity-dependent and requires glutamate binding to NMDARs (Barria and Malinow, 2002).

Here we use electrophysiologically tagged NMDARs expressed in organotypic hippocampal slices to identify the domains determining the mode of synaptic incorporation. Our findings identify molecular differences between GluN2A and GluN2B that determine the mode of synaptic incorporation of NMDARs and suggest a novel mechanism for regulating activity-driven changes and forward trafficking of NMDARs to the synapse.

\section{Materials and Methods}

Chimeric subunits

Chimeric subunits were constructed using GFP-tagged GluN2Bwt and GluN2Awt (Barria and Malinow, 2002) and PCR-based methods. All subunits are cloned into the mammalian expression vector pCI (Promega). A description of the chimeras is provided below.

GluN2A-CTBc3 and GluN2B-CTAc3. The last third of the C terminus of GluN2A (P1222-V1464) and GluN2B (P1219-V1482) were exchanged.

GluN2A-CTB and GluN2B-CTA. The entire C terminus of GluN2A (L794-V1464) and GluN2B (L795-V1482) were exchanged.

GluN2A intra B. Mutations N587C, K590D, K592R, A593E, and H595G were introduced in GluN2A-CTB.

GluN2B intra A. Mutations C588N, D591K, R593K, E594A, and G596H were introduced in GluN2B-CTA.

NTB-GluN2A and NTA-GluN2B. The entire N terminus of GluN2A (M1-V522) and GluN2B (M1-V523) were exchanged. 
B-loop-GluN2A and A-loop-GluN2B. The N terminus of GluN2A-CTB (M1-K628) and GluN2B-CTA (M1-K629) were swapped.

B-loop-GluN2A sites 1-3. Predicted individual glycosylation sites present in the B-loop were modified in B-loop-GluN2A as follows: site 1, N675H/ F677Y; site 2, A700P/ E701Y; site 3, M739K.

A-loop-GluN2B site 1. This predicted glycosylation site, absent in A-loop, was mutated in A-loop-GluN2B to mimic site 1 of GluN2B as follows: site 1, H674N/ Y676F.

A-loop-GluN2B sites 2 and 3. Predicted individual glycosylation sites were modified in A-loop-GluN2B as follows: site 2, P699A/ Y700E; site 3, K738M.

\section{Slice cultures and transfection}

Organotypic hippocampal slices were prepared according to University of Washington guidelines from 6-d-old (p6) Sprague Dawley male and female rats as described previously (Stoppini et al., 1991). After 3-5 din culture, slices were transfected using a biolistic particle delivery system (Woods and Zito, 2008) and cultured for an additional $48-72 \mathrm{~h}$. A plasmid DNA, ratio 1:1 of GluN1 and GluN2 subunits, was used (70-100 $\mu \mathrm{g}$ each). When necessary, APV (Tocris Bioscience) was added immediately after transfection and replenished every $24 \mathrm{~h}$.

\section{Immunoblot}

Homogenates from four slices cultured for different lengths of time were immunoblotted with mouse monoclonal anti-NMDAR2A antibody 2F6-3D5 (provided by Dr. Georg Köhr, Max Plank Institute, Heidelberg, Germany) or anti $\alpha$-actin antibody (Millipore Bioscience Research Reagents).

\section{Electrophysiology}

Whole-cell recordings from CA1 neurons were obtained under visual guidance. The recording chamber was perfused with artificial CSF (ACSF) containing the following: 119 $\mathrm{mm} \mathrm{NaCl}, 2.5 \mathrm{~mm} \mathrm{KCl}, 4 \mathrm{~mm} \mathrm{CaCl}, 4 \mathrm{~mm} \mathrm{MgCl}_{2}, 26 \mathrm{~mm} \mathrm{NaHCO}_{3}, 1$ $\mathrm{mm} \mathrm{NaH}{ }_{2} \mathrm{PO}_{4}, 11 \mathrm{~mm}$ glucose, $100 \mu \mathrm{m}$ picrotoxin (Tocris Bioscience), $2 \mu \mathrm{M}$ 2-chloroadenosine, $\mathrm{pH} 7.4$, gassed with $5 \% \mathrm{CO}_{2} / 95 \% \mathrm{O}_{2}$ at room temperature $\left(20-25^{\circ} \mathrm{C}\right)$. Intracellular recording solution contained the following (in mM): 115 cesium methanesulfonate, $20 \mathrm{CsCl}, 10 \mathrm{HEPES}$, $2.5 \mathrm{MgCl}_{2} 2 \mathrm{MgATP}, 2 \mathrm{Na}_{2} \mathrm{ATP}, 0.4 \mathrm{Na}_{3} \mathrm{GTP}, 10$ sodium phosphocreatine, 5 QX-314, and 0.6 EGTA (pH 7.25 and $310 \mathrm{mmol} / \mathrm{Kg}$ ). Synaptic responses were evoked with bipolar cluster electrodes (FHC) placed over Schaffer collateral fibers.

Synaptic incorporation index is mean current from a $50 \mathrm{~ms}$ window $110 \mathrm{~ms}$ after the stimulus artifact in evoked EPSCs recorded at $-60 \mathrm{mV}$ [recombinant NMDAR (rNMDAR)], normalized to the peak of the EPSC that represents activation of endogenous AMPARs (eAMPARs).

Statistical analysis

All results are represented as mean \pm SEM. Statistical differences of these means were determined using Student's $t$ test. Significance was set at $p \leq 0.05$.

\section{Results}

\section{Synaptic incorporation of GluN2A receptors}

\section{is activity-dependent}

In hippocampal slices prepared from $\mathrm{p} 6$ rats, expression of GluN2A is very low and increases rapidly after a week in culture (Fig. 1A). As GluN2A becomes expressed, it is incorporated into
B

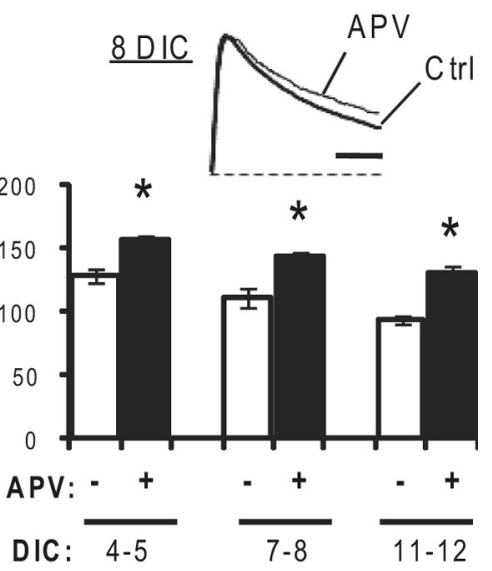

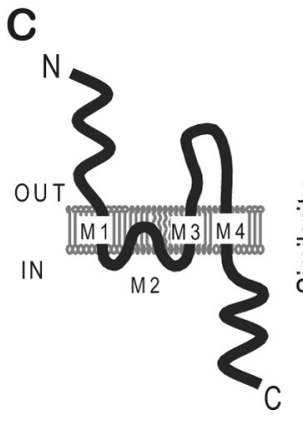

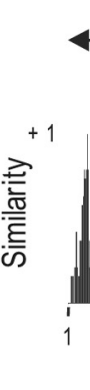

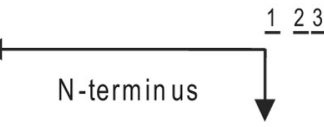

$\underline{1} \underline{2} \underline{3} \quad \underline{4}$

$\underline{4}$

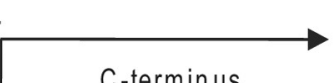

C-terminus

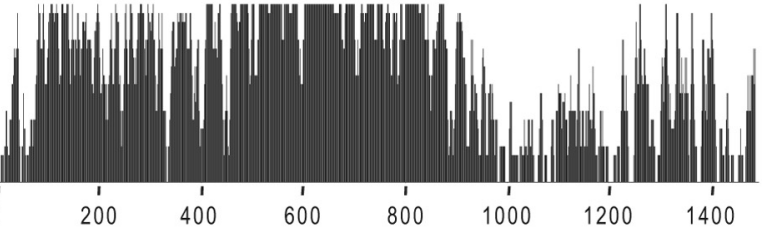

Amino Acid Number

Figure 1. Synaptic incorporation of GluN2A receptors is regulated by synaptic activity. $A$, Expression of GluN2A in cultured organotypic ippocampal slices. Quantitative immunoblot of endogenous GluN2A from hippocampal slices prepared at p6 and cultured as indicated.

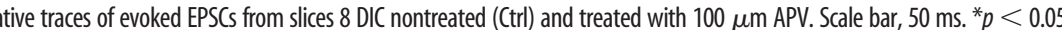
( residue at a given alignment position in each aligned sequence, depending on whether the residue is identical $(+1)$, similar $(0.5)$, or weakly similar (0.2) to the corresponding residue of the consensus sequence. The $\mathrm{N}$ terminus, the C terminus, and four membrane segments are indicated.

synapses, as indicated by the shortening of the decay time of NMDAR-dependent EPSC (Fig. $1 B$ ). To reduce the level of neuronal activity acting on NMDARs, we treated organotypic slices with APV, a competitive NMDAR antagonist (Davies and Watkins, 1982), for 3 d before recording. NMDAR-dependent EPSCs from APV-treated slices exhibited longer decay times compared with EPSCs from control, age-matched slices (Fig. $1 B$ ), indicating that APV treatment blocked synaptic incorporation of GluN2A receptors. This treatment did not affect expression of the GluN2A subunit (Fig. 1A). These results support the view that incorporation of GluN2A into synapses is regulated by synaptic activity and can be blocked by APV. Similar results have been described using overexpression of electrophysiologically tagged NMDARs in organotypic cultured hippocampal slices (Barria and Malinow, 2002).

To identify domains conferring the activity-dependent or activity-independent modes of synaptic incorporation to GluN2A and GluN2B, respectively, we expressed electrophysiologically tagged NMDARs containing chimeric GluN2 subunits in organotypic hippocampal slices.

A mutant of GluN1 (GluN1 N598R) was used as an electrophysiological tag (etag). This mutation eliminates the normal magnesium blockade of NMDARs observed at hyperpolarized potentials (Burnashev et al., 1992; Single et al., 2000). NMDARs 


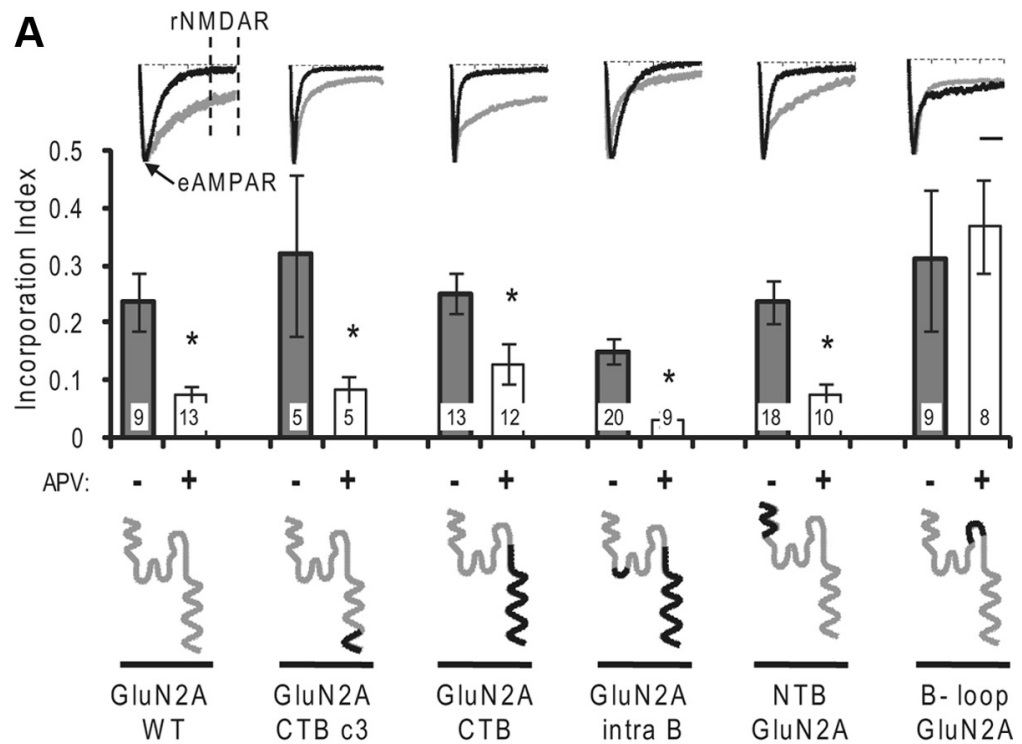

\section{B}

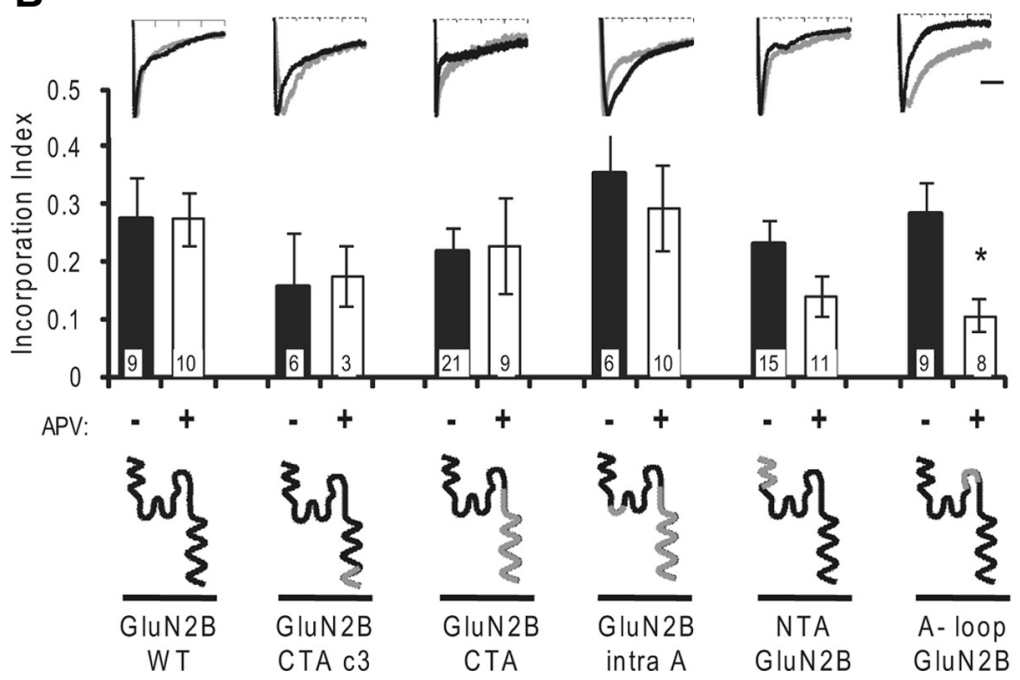

Figure 2. Synaptic incorporation of GluN2 chimeric subunits. $A$, GluN2A-based chimeric subunits. Synaptic incorporation index for wild-type and chimeric GluN2A with different domains of GluN2B. Slices were cotransfected with etag-GluN1 and wild-type GluN2A or chimeric GluN2A subunits and expressed in control conditions or $100 \mu \mathrm{M}$ APV. Incorporation index is calculated as the ratio of the late component (rNMDAR) to the early peak of the response (eAMPAR). Treatment of the slices with APV during the expression period (white bars) blocks synaptic incorporation of wild-type GluN2A (far left). Number of cells as indicated. Insets, Representative EPSCS. Black traces are from slices treated with APV during the expression period. $\boldsymbol{B}$, GluN2B-based chimeric subunits. Synaptic incorporation index for wild-type GluN2B and chimeric GluN2B with different domains of GluN2A. Treatment of the slices with $100 \mu \mathrm{M}$ APV during the expression period (white bars) does not block incorporation of wild-type GluN2B (far left). Insets, Representative EPSCs as in $\boldsymbol{A}$. Scale bars, 50 ms. ${ }^{*} p<0.05$ Student's $t$ test.

were also optically tagged with GFP to identify transfected CA1 neurons. In transfected cells, evoked EPSCs at hyperpolarized potentials $(-60 \mathrm{mV})$ exhibit a fast component due to the activation of eAMPARs and a slow component that reflects the activation of rNMDARs (Fig. $2 A$, inset). Previously reported data show that etag-GluN1 does not heteromerize with endogenous GluN2 subunits; therefore, it is inserted into synapses only when it heteromerizes with recombinant GluN2 subunits (Barria and Malinow, 2002). An incorporation index was calculated by measuring the late component of the EPSC (etag-NMDARs) normalized to the peak amplitude of the earlier component (endogenous AMPARs). We used this simple and quantitative assay to identify the domains on GluN2 subunits controlling the mode of synaptic incorporation.

\section{Molecular determinants of NMDAR synaptic incorporation}

At hyperpolarized potentials, endogenous NMDARs are blocked by $\mathrm{Mg}^{+2}$; therefore, as reported before, synaptic incorporation of recombinant etagged GluN2A and GluN2B can be measured as a late current from EPSCs recorded at $-60 \mathrm{mV}$ (Fig. 2, far left insets, gray traces). Incubation of slices with APV during the expression period blocks incorporation of recombinant GluN2A-containing receptors but not GluN2B-containing receptors (Fig. 2, far left) (Barria and Malinow, 2002).

GluN2 subunits A and B are highly similar, with $69 \%$ of identical or conserved amino acids (Ishii et al., 1993). This similarity is especially high at the four membrane domains (M1-M4) and connecting loops (94\%), moderate at the $\mathrm{N}$ terminus (80\%), and lowest at the C-terminal region (54\%) (Fig. 1C).

We first swapped the last portion of the $\mathrm{C}$ terminus, which contains a PDZ binding domain and internalization sequences that control stabilization and removal from the plasma membrane (Lavezzari et al., 2004). Swapping this domain had no effect on the insertion behavior. Chimeric GluN2A with the last portion of GluN2B C terminus is not incorporated into synapses when slices are treated with APV (Fig. 2A). Supporting the idea that this portion of GluN2 subunits does not regulate the mode of insertion, chimeric GluN2B with the last portion of GluN2A C terminus incorporates into synapses in a constitutive manner (Fig. 2B). This result suggests that the regulatory domain of synaptic insertion resides away from previously described internalization and synapse stabilization sequences. Swapping the full $\mathrm{C}$ terminus of GluN2A and GluN2B also did not alter the mode of synaptic incorporation of these chimeric NMDARs, indicating that the domain controlling the mode of insertion is not located in the intracellular C terminus (Fig. 2).

Two small intracellular loops, one connecting M1 with the re-entering loop that forms the pore of the channel (M2) and the other connecting M2 with M3 (Fig. 1C, topology model), also face the cytosol and therefore could be involved in a cytosolic controlling mechanism. These two loops, 21 and 10 aa long, are identical between GluN2A and GluN2B with the exception of six residues in the larger loop. All six residues in the larger intracellular loop were swapped along with the $\mathrm{C}$ terminus to generate chimeric GluN2 subunits with all intracellular domains corresponding to one subunit, while the extracellular domains corresponded to the other. Chimeric GluN2A subunit with all the intracellular domains matching GluN2B was incorporated into synapses and its incorporation was blocked by APV treatment, similar to wildtype GluN2A. This indicates that the domains controlling activity-dependent incorporation must be extracellular. Con- 
firming this, chimeric GluN2B with all the intracellular portions matching those of GluN2A was accordingly incorporated in a constitutive manner and not blocked by APV treatment, similar to wild-type GluN2B (Fig. 2). Thus, our data indicate that the domain determining the mode of synaptic incorporation is not located on GluN2 domains facing the cytosol.

The $\mathrm{N}$ terminus and the large loop connecting M3 and M4 face the lumen of the endoplasmic reticulum and transport organelles and the extracellular milieu once the receptor is inserted in the plasma membrane. Replacing the entire $\mathrm{N}$ terminus of GluN2A (NTD and S1 domains) with that of GluN2B had no effect on synaptic insertion. Thus, synaptic incorporation of NTBGluN2A, like wild-type GluN2A, is activitydependent. Synaptic incorporation of chimeric GluN2B with the $\mathrm{N}$ terminus of GluN2A, NTA-GluN2B, was not blocked by APV, indicating that its incorporation is activity-independent, like wild-type GluN2B (Fig. 2B).

The extracellular loop between M3 and M4 is 168 aa long in GluN2A and 169 in GluN2B, with $93 \%$ of identity or similarity. Chimeric GluN2A carrying the GluN2B loop (B-loop-GluN2A) is inserted into synapses, but, in contrast to wild-type GluN2A, APV does not block its incorporation. Thus, the M3-M4 loop of GluN2B confers to GluN2A the constitutive mode of synaptic incorporation characteristic of GluN2B receptors (Fig. 2A). In a symmetrical manner, chimeric GluN2B carrying the loop from GluN2A (A-loop-GluN2B) behaves like wild-type GluN2A and APV blocks its incorporation into synapses (Fig. 2B). These experiments indicate that the domain selecting the mode of synaptic incorporation faces the intraluminal side of transport organelles and lies in the loop connecting M3 and M4 and not in the N terminus.

The M3-M4 loop is almost identical between GluN2A and GluN2B subunits with 22 different residues, of which only 12 are nonconservative changes. We looked for conserved sequences that could participate in cellular processes that regulate protein assembly, sorting, or transport to the extracellular membrane. $N$ glycosylation is a known process involved in regulating proper protein folding, stability, quality control, and post-Golgi trafficking to plasma membranes of polarized cells (Vagin et al., 2009) and predicted glycosylation sites are present on NMDARs subunits (Moriyoshi et al., 1991; Monyer et al., 1992; Ishii et al., 1993; Everts et al., 1997).

Using NetNGlyc server (Blom et al., 2004) we found three predicted sites for $\mathrm{N}$-linked glycosylation in the M3-M4 loop
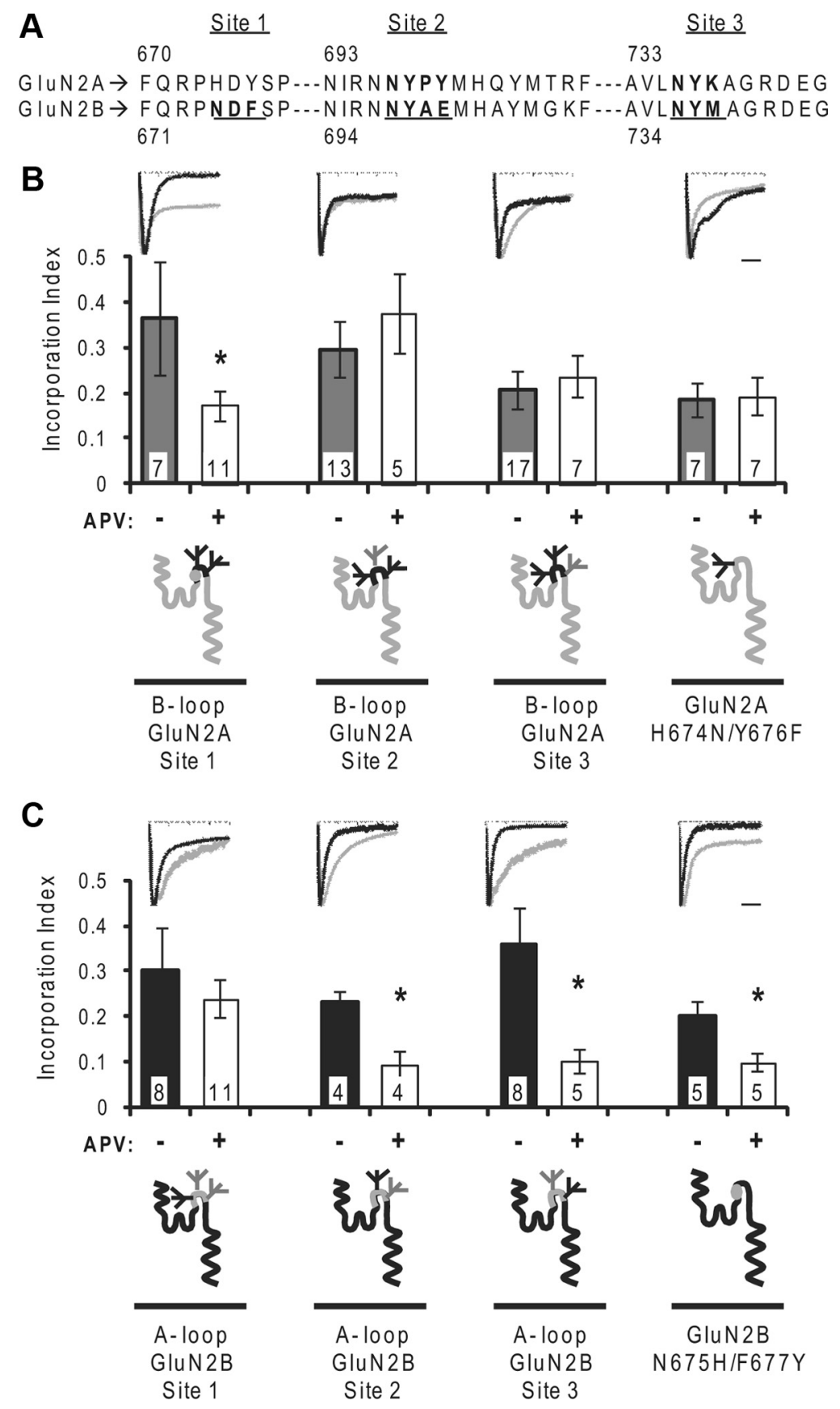

Figure 3. Molecular determinant of synaptic incorporation. A, Predicted $N$-glycosylation sites in M3-M4 loop. Comparison of GluN2A and GluN2B sequences at the predicted $N$-glycosylation sites (bold). Note the absence of site 1 in GluN2A. $\boldsymbol{B}$, Mutations of predicted $N$-glycosylation sites on the B-loop. Synaptic incorporation index of B-loop-GluN2A-based mutants and double-mutant GluN2A H674N/Y676F. Treatment of the slices with $100 \mu \mathrm{M}$ APV during the expression period (white bars) blocks incorporation when site 1of B-loop is removed (far left). Number of cells as indicated. Insets, Representative EPSCs. Black traces are from slices treated with APV during the expression period. C, Mutations of predicted $\mathrm{N}$-glycosylation sites on the A-loop. Synaptic incorporation index of A-loop-GluN2B-based mutants and double-mutant GluN2B N675H/F677Y. Treatment of the slices with $100 \mu \mathrm{m} \mathrm{APV}$ during the expression period (white bars) does not block incorporation when site 1 of B-loop is added (far left). Number of cells as indicated. Insets, Representative EPSCs as in B. Scale bars, 50 ms. ${ }^{*} p<0.05$ Student's $t$ test.

domain of GluN2B located at N675 (site 1), N698 (site 2), and N737 (site 3). Two of these sites, 2 and 3, are also present in GluN2A but have nonconserved substitutions around the asparagines. GluN2A lacked site 1 completely (Fig. $3 A$ ).

In the chimeric GluN2A receptor containing the GluN2B loop, we mutated the residues of site 1 to those present on GluN2A (N675H and F677Y) to eliminate this potential 
$\mathrm{N}$-glycosylation site. Removal of site 1 in the B-loopp-GluN2A chimera was sufficient to block synaptic incorporation by treatment with APV (Fig. 3B, far left). Conversely, adding site 1 of GluN2B into the A-loop-GluN2B chimera (H674N and Y676F) made the chimera incorporate into synapses in a constitutive manner, the same as wild-type GluN2B (Fig. 3C, far left). Mutations in sites 2 and 3 had no effect on the mode of synaptic incorporation (Fig. $3 B, C$ ).

A double mutation in wild-type GluN2B that removes site 1 $(\mathrm{N} 675 \mathrm{H} / \mathrm{F} 677 \mathrm{Y})$ removed the constitutive manner of synaptic incorporation of this receptor. Introduction of site 1 onto wild-type GluN2A (H674N/Y676F) caused the receptor to incorporate into synapses in an activity-independent manner (Fig. $3 B, A$, far right). These data suggest that a predicted glycosylation site at N675 in the M3-M4 loop domain of GluN2B, which is not found in GluN2A, is necessary and sufficient to direct GluN2B-containing receptors to synapses in an activity-independent manner. Absence of this potential $N$-glycosylation site gives NMDARs a phenotype that requires synaptic activity to incorporate into synapses.

\section{Discussion}

Synaptic incorporation of GluN2A-containing receptors requires synaptic activity or sensory experience (for review, see Yashiro and Philpot, 2008). In contrast, GluN2B-containing receptors are incorporated in a constitutive manner (Barria and Malinow, 2002). We used a simple quantitative assay to identify the molecular determinants that segregate GluN2 subunits into activitydependent and activity-independent trafficking pathways.

The intracellular C termini of GluN2 and GluN1 subunits regulate retention in the endoplasmic reticulum (Wenthold et al., 2003) and synaptic stabilization via PDZ binding domains (Barria and Malinow, 2002; Prybylowski et al., 2002). In addition, the $\mathrm{C}$ termini of GluN2 subunits regulate synaptic NMDARs via tyrosine-based internalization signals (Carroll and Zukin, 2002; Prybylowski et al., 2005; Sanz-Clemente et al., 2010). We found that domains facing the cytoplasm do not regulate the mode of synaptic incorporation of NMDARs. Unexpectedly, we found that the extracellular loop between M3 and M4 of GluN2A and GluN2B was sufficient to determine the incorporation phenotype of these GluN2 subunits. Some of the differences in amino acid sequence in the loops occur on or around predicted $\mathrm{N}$-glycosylation sites, a mechanism used by chaperone proteins in the Golgi to identify and move proteins to distinct trafficking vesicles (Martínez-Maza et al., 2001; Nathanson, 2008). GluN2 subunits are glycosylated proteins (Clark et al., 1998) and glycosylation can affect the NMDA receptor's assembly and function (Chazot et al., 1995; Everts et al., 1997; Standley and Baudry, 2000; Gascón et al., 2007). In polarized cells, a single glycosylation site can target proteins to the apical or basolateral membrane. Much of this sorting is thought to occur through interaction with lectins, which recognize glycosylated proteins and can direct their association with lipid rafts (Clark et al., 1998; Vagin et al., 2009).

We identified a putative $N$-glycosylation site in GluN2B (N675) and H674 of GluN2A, as the molecular determinants controlling the mode of synaptic incorporation. These residues lie in the M3-S2 linker region outside the D2 domain of their respective ligand binding domains. According to the crystal structure of the NMDAR GluN1/GluN2 dimer, these residues lie on the surface in a position potentially accessible to enzymatic modification (Furukawa et al., 2005).

Our data suggest that specific $N$-glycosylation of the GluN2B subunit could regulate receptor sorting and trafficking within the cell via differential interaction of GluN2 subunits with intralumi- nal proteins. This could segregate NMDARs into separate trafficking pathways with different requirements to reach the synaptic membrane. Different secretory pathways have also been proposed for AMPA-type glutamate receptors (Malinow et al., 2000 ) and their assembly and proper intracellular trafficking can be controlled by intraluminal sites (Greger and Esteban, 2007). Segregation of proteins into different secretory pathways could be a general mechanism to position glutamate receptors in different compartments that will react differently to synaptic activity.

\section{References}

Al-Hallaq RA, Conrads TP, Veenstra TD, Wenthold RJ (2007) NMDA diheteromeric receptor populations and associated proteins in rat hippocampus. J Neurosci 27:8334-8343.

Barria A, Malinow R (2002) Subunit-specific NMDA receptor trafficking to synapses. Neuron 35:345-353.

Barria A, Malinow R (2005) NMDA receptor subunit composition controls synaptic plasticity by regulating binding to CaMKII. Neuron 48:289-301.

Bliss TV, Collingridge GL, Morris RG (2003) Introduction: long-term potentiation and structure of the issue. Philos Trans R Soc Lond B Biol Sci 358:607-611.

Blom N, Sicheritz-Pontén T, Gupta R, Gammeltoft S, Brunak S (2004) Prediction of post-translational glycosylation and phosphorylation of proteins from the amino acid sequence. Proteomics 4:1633-1649.

Burnashev N, Schoepfer R, Monyer H, Ruppersberg JP, Günther W, Seeburg PH, Sakmann B (1992) Control by asparagine residues of calcium permeability and magnesium blockade in the NMDA receptor. Science 257:1415-1419.

Burnashev N, Zhou Z, Neher E, Sakmann B (1995) Fractional calcium currents through recombinant GluR channels of the NMDA, AMPA and kainate receptor subtypes. J Physiol 485:403-418.

Carroll RC, Zukin RS (2002) NMDA-receptor trafficking and targeting: implications for synaptic transmission and plasticity. Trends Neurosci 25:571-577.

Chatterton JE, Awobuluyi M, Premkumar LS, Takahashi H, Talantova M, Shin Y, Cui J, Tu S, Sevarino KA, Nakanishi N, Tong G, Lipton SA, Zhang D (2002) Excitatory glycine receptors containing the NR3 family of NMDA receptor subunits. Nature 415:793-798.

Chazot PL, Cik M, Stephenson FA (1995) An investigation into the role of $\mathrm{N}$-glycosylation in the functional expression of a recombinant heteromeric NMDA receptor. Mol Membr Biol 12:331-337.

Clark RA, Gurd JW, Bissoon N, Tricaud N, Molnar E, Zamze SE, Dwek RA, McIlhinney RA, Wing DR (1998) Identification of lectin-purified neural glycoproteins, GPs 180, 116, and 110, with NMDA and AMPA receptor subunits: conservation of glycosylation at the synapse. J Neurochem 70:2594-2605.

Cline H, Haas K (2008) The regulation of dendritic arbor development and plasticity by glutamatergic synaptic input: a review of the synaptotrophic hypothesis. J Physiol 586:1509-1517.

Cull-Candy S, Brickley S, Farrant M (2001) NMDA receptor subunits: diversity, development and disease. Curr Opin Neurobiol 11:327-335.

Davies J, Watkins JC (1982) Actions of D and L forms of 2-amino-5phosphonovalerate and 2-amino-4-phosphonobutyrate in the cat spinal cord. Brain Res 235:378-386.

Erreger K, Dravid SM, Banke TG, Wyllie DJ, Traynelis SF (2005) Subunitspecific gating controls rat NR1/NR2A and NR1/NR2B NMDA channel kinetics and synaptic signalling profiles. J Physiol 563:345-358.

Everts I, Villmann C, Hollmann M (1997) N-glycosylation is not a prerequisite for glutamate receptor function but is essential for lectin modulation. Mol Pharmacol 52:861-873.

Flint AC, Maisch US, Weishaupt JH, Kriegstein AR, Monyer H (1997) NR2A subunit expression shortens NMDA receptor synaptic currents in developing neocortex. J Neurosci 17:2469-2476.

Foster KA, McLaughlin N, Edbauer D, Phillips M, Bolton A, ConstantinePaton M, Sheng M (2010) Distinct roles of NR2A and NR2B cytoplasmic tails in long-term potentiation. J Neurosci 30:2676-2685.

Furukawa H, Singh SK, Mancusso R, Gouaux E (2005) Subunit arrangement and function in NMDA receptors. Nature 438:185-192.

Gascón S, García-Gallo M, Renart J, Díaz-Guerra M (2007) Endoplasmic reticulum-associated degradation of the NR1 but not the NR2 subunits of 
the $\mathrm{N}$-methyl-D-aspartate receptor induced by inhibition of the $\mathrm{N}$-glycosylation in cortical neurons. J Neurosci Res 85:1713-1723.

Greger IH, Esteban JA (2007) AMPA receptor biogenesis and trafficking. Curr Opin Neurobiol 17:289-297.

Ishii T, Moriyoshi K, Sugihara H, Sakurada K, Kadotani H, Yokoi M, Akazawa C, Shigemoto R, Mizuno N, Masu M (1993) Molecular characterization of the family of the N-methyl-D-aspartate receptor subunits. J Biol Chem 268:2836-2843.

Kim MJ, Dunah AW, Wang YT, Sheng M (2005) Differential roles of NR2Aand NR2B-containing NMDA receptors in Ras-ERK signaling and AMPA receptor trafficking. Neuron 46:745-760.

Kutsuwada T, Sakimura K, Manabe T, Takayama C, Katakura N, Kushiya E, Natsume R, Watanabe M, Inoue Y, Yagi T, Aizawa S, Arakawa M, Takahashi T, Nakamura Y, Mori H, Mishina M (1996) Impairment of suckling response, trigeminal neuronal pattern formation, and hippocampal LTD in NMDA receptor epsilon 2 subunit mutant mice. Neuron 16:333-344.

Lavezzari G, McCallum J, Dewey CM, Roche KW (2004) Subunit-specific regulation of NMDA receptor endocytosis. J Neurosci 24:6383-6391.

Malinow R, Mainen ZF, Hayashi Y (2000) LTP mechanisms: from silence to four-lane traffic. Curr Opin Neurobiol 10:352-357.

Martínez-Maza R, Poyatos I, López-Corcuera B, Núñez E, Giménez C, Zafra F, Aragón C (2001) The role of N-glycosylation in transport to the plasma membrane and sorting of the neuronal glycine transporter GLYT2. J Biol Chem 276:2168-2173.

Monyer H, Sprengel R, Schoepfer R, Herb A, Higuchi M, Lomeli H, Burnashev N, Sakmann B, Seeburg PH (1992) Heteromeric NMDA receptors: molecular and functional distinction of subtypes. Science 256:1217-1221.

Monyer H, Burnashev N, Laurie DJ, Sakmann B, Seeburg PH (1994) Developmental and regional expression in the rat brain and functional properties of four NMDA receptors. Neuron 12:529-540.

Moriyoshi K, Masu M, Ishii T, Shigemoto R, Mizuno N, Nakanishi S (1991) Molecular cloning and characterization of the rat NMDA receptor. Nature 354:31-37.

Nathanson NM (2008) Synthesis, trafficking, and localization of muscarinic acetylcholine receptors. Pharmacol Ther 119:33-43.

Prybylowski K, Fu Z, Losi G, Hawkins LM, Luo J, Chang K, Wenthold RJ, Vicini S (2002) Relationship between availability of NMDA receptor subunits and their expression at the synapse. J Neurosci 22:8902-8910.

Prybylowski K, Chang K, Sans N, Kan L, Vicini S, Wenthold RJ (2005) The synaptic localization of NR2B-containing NMDA receptors is controlled by interactions with PDZ proteins and AP-2. Neuron 47:845-857.

Sanz-Clemente A, Matta JA, Isaac JT, Roche KW (2010) Casein kinase 2 regulates the NR2 subunit composition of synaptic NMDA receptors. Neuron 67:984-996.

Sheng M, Cummings J, Roldan LA, Jan YN, Jan LY (1994) Changing subunit composition of heteromeric NMDA receptors during development of rat cortex. Nature 368:144-147.

Single FN, Rozov A, Burnashev N, Zimmermann F, Hanley DF, Forrest D, Curran T, Jensen V, Hvalby O, Sprengel R, Seeburg PH (2000) Dysfunctions in mice by NMDA receptor point mutations NR1(N598Q) and NR1(N598R). J Neurosci 20:2558-2566.

Sobczyk A, Scheuss V, Svoboda K (2005) NMDA receptor subunitdependent $[\mathrm{Ca} 2+]$ signaling in individual hippocampal dendritic spines. J Neurosci 25:6037-6046.

Standley S, Baudry M (2000) The role of glycosylation in ionotropic glutamate receptor ligand binding, function, and trafficking. Cell Mol Life Sci 57:1508-1516.

Stocca G, Vicini S (1998) Increased contribution of NR2A subunit to synaptic NMDA receptors in developing rat cortical neurons. J Physiol 507:13-24.

Stoppini L, Buchs PA, Muller D (1991) A simple method for organotypic cultures of nervous tissue. J Neurosci Methods 37:173-182.

Traynelis SF, Wollmuth LP, McBain CJ, Menniti FS, Vance KM, Ogden KK, Hansen KB, Yuan H, Myers SJ, Dingledine R (2010) Glutamate receptor ion channels: structure, regulation, and function. Pharmacol Rev 62:405-496.

Vagin O, Kraut JA, Sachs G (2009) Role of N-glycosylation in trafficking of apical membrane proteins in epithelia. Am J Physiol Renal Physiol 296:F459-469.

Wenthold RJ, Prybylowski K, Standley S, Sans N, Petralia RS (2003) Trafficking of NMDA receptors. Annu Rev Pharmacol Toxicol 43:335-358.

Woods G, Zito K (2008) Preparation of gene gun bullets and biolistic transfection of neurons in slice culture. J Vis Exp 12:675.

Yashiro K, Philpot BD (2008) Regulation of NMDA receptor subunit expression and its implications for LTD, LTP, and metaplasticity. Neuropharmacology 55:1081-1094.

Zhou Y, Takahashi E, Li W, Halt A, Wiltgen B, Ehninger D, Li GD, Hell JW, Kennedy MB, Silva AJ (2007) Interactions between the NR2B receptor and CaMKII modulate synaptic plasticity and spatial learning. J Neurosci $27: 13843-13853$. 